\title{
Aberrant expression and function of TCF4 in the proliferation of hepatocellular carcinoma cell line BEL-7402
}

\author{
Dong Hong ZHAO, Jian Jun HONG, Shi Ying GUO, Run Lin YANG, Jun YUAN, Chuan Jun WEN, \\ Kai Ya ZHOU, Chao Jun LI*
}

The Jiangsu Key Laboratory of Molecular Medical Biotechnology, College of Life Science, Nanjing Normal University, Nanjing 210097, Jiangsu, China.

\begin{abstract}
Wnt signaling pathway is essential for development and tumorigenesis, however, this signaling pathway in the progress of hepatocellular carcinoma (HCC) remains unclear. In this paper, we studied the function of human T-cell transcription factor-4 (TCF4), a key factor of Wnt signaling pathway, on the proliferation of HCC cell line. We showed that the expression of TCF4 mRNA in HCC cell line BEL-7402 was higher than that in immortalized normal liver cell line L02. Blockage of Wnt pathway by $\triangle \mathrm{NTCF} 4$, a dominant negative TCF4, could suppress BEL-7402 cells growth and decrease the expression of cyclin DI and c-myc, two of target genes of Wnt pathway. On the other hand, stimulating Wnt pathway by introducing a degradation-resistant $\beta$-catenin S37A could increase BEL-7402 cells proliferation. But all the treatments had no effect on L02 cells. Our data indicated that TCF4 might be another key factor in Wnt pathway involved in HCC cells proliferation and TCF4 could be an effective therapeutic target for suppressing the growth of hepatocellular cancers.
\end{abstract}

Keywords: Wnt signaling pathway, $\beta$-catenin, dominant negative TCF4.

\section{INTRODUCTION}

Wnt signaling pathway plays a critical role in directing cell fates during embryogenesis. In addition, inappropriate activation of Wnt signaling pathway results in a variety of human cancers by turning on genes encoding oncoproteins and cell-cycle regulators[1-3]. The protein $\beta$-catenin is a major component of the Wnt signaling pathway, which is involved in two major functions: cell adhesion and Wnt signal transduction $[4,5]$. In the absence of Wnt signal, $\beta$ catenin is localized in cell-cell junctions but very low in cytoplasm and nucleus because excess $\beta$-catenin in cytoplasm is targeted to proteasome-mediated degradation by a complex containing GSK-3 $\beta[6]$, Axin[7] and APC[8]. Activation of Wnt signaling results in the inactivation of GSK-3 $\beta$, which in turn leads to the stabilization of cytoplasmic $\beta$-catenin. The accumulation of $\beta$-catenin promotes its nuclear translocation where it associates with LEF/TCF transcription factors and activates Wnt target genes $[9,10]$.

HCC is one of the most common fatal cancers worldwide. Inappropriate activation of Wnt signaling pathway has been implicated recently in the development of HCC. $\beta$-catenin gene mutation was often found in HCC, which

\footnotetext{
"Corresponding author: Chao Jun LI,

Tel: 008625 3598779, Fax: 0086253598812 ,

E-mail: licj@njnu.edu.cn.
}

resulted in the protein accumulation in cytoplama and thus activating of Wnt signaling pathway[11]. Several components related to $\beta$-catenin degradation were also found to be mutated during hepatocellular carcinogenesis. Mutation in Axin gene resulting in $\beta$-catenin accumulation has been reported in $\mathrm{HCC}$ [12]. But APC gene was rarely mutated in HCC although its mutation occurred in most colon cancers[12].

So other component of Wnt signaling pathway might be involved the proliferation of HCC cell. The formation of a complex between $\beta$-catenin and transcription factors of TCF/LEF family is a key regulatory event in the Wnt signaling pathway[13]. TCF/LEF family include LEF-1, TCF1, TCF3, TCF3 a, TCF4, which all contain DNAbinding high mobility group (HMG) domain and a $\beta$-catenin binding domain[14]. TCF4 is an important member of this family. The N-terminal 53 amino acids of TCF4 bind with high affinity to $\beta$-catenin[15]. TCF4 and $\beta$-catenin form a complex to transactivate target genes expression including cell cycle regulating genes cyclin D1 and c-myc. We found that Wnt signaling was aberrantly activated in HCC cells BEL-7402 because both the high expression of TCF4 and the accumulation of $\beta$-catenin were observed. The results suggested that activation of TCF 4 coupled with $\beta$ catenin expression may contribute to the development ofHCC. It was also worth noting that TCF4 may be a potential target of gene therapy for HCC. 


\section{MATERIALS AND METHODS}

\section{Cells, plasmids and antibodies}

Immortalized normal human liver cells L02 and HCC cells BEL7402 were purchased from Shanghai Institute of Cell Biology. They were maintained in Dulbecco's modified Eagle's medium supplemented with $10 \% \mathrm{NCS}$. The cultures were kept in a $5 \% \mathrm{CO}_{2}$ and $95 \%$ air humidified incubator at $37^{\circ} \mathrm{C}$.

The wild type TCF reporter plasmid (TOPFLASH) and mutated reporter plasmid (FOPFLASH) were obtained from Upstate biotechnology (NY, USA). The cDNA encoding $\beta$-cateninS37A was a gift of Dr. Xin Yuan FU and subcloned into expression vector pcDNA3. The control reporter plasmid $\beta$-gal-CMV was a gift of Dr. Zhi-Ming YIN . The constructs of pcDNA3TCF4, pcDNA3 dominant negative TCF4 and the CyclinD1 reporter plasmid were constructed by Dr. O. Tetsu and Dr. F. McCormick who got the human TCF4 cDNA fragment and cyclinD1 promoter fragment from Dr. $\mathrm{H}$. Clevers, Dr. A. Arnold and Dr. R. Pestell.

Anti- $\beta$-catenin polyclonal antibody, anti-cyclinD1 monoclonal antibody and anti-c-Myc monoclonal antibody were obtained from Santa Cruz (California, USA). Anti- $\beta$-tubulin antibody was purchased from Sigma (MO, USA).

\section{Immunofluorescence staining of hepatoma cell lines}

The HCC cell line BEL-7402 and the normal liver cell line L02 were washed in PBS, then fixed and permeabilized. Cells were incubated for $1 \mathrm{~h}$ in blocking solution [PBS, 3\% BSA (wt/vol)], and then with a rabbit polyclonal anti- $\beta$-catenin antibody (dilution 1:200) at room temperature in a moist chamber. The cells were washed several times in PBS- $0.05 \%$ (vol/ $/ \mathrm{vol}$ ) Tween 20, and incubated for $45 \mathrm{~min}$ with anti-rabbit fluorescein isothiocyanate antibody (dilution 1:500). The cells were examined under a leica fluorescence microscope and photographed. For quantitation of $\beta$-catenin in cytosole, the fluorescence intensity was measured with Image Analysis Software. At least 50 cells were examined in each experiment.

\section{Western blot analysis}

Cells were washed and lysed in lysis buffer $(20 \mathrm{mM}$ Tris- $\mathrm{HCl}$, pH 8.0, $75 \mathrm{~m} M \mathrm{NaCl}, 1.5 \mathrm{~m} M \mathrm{MgCl}_{2}, 1 \mathrm{~m} M$ EGTA, 1.0\% NP-40, 1 $\mathrm{m} M$ PMSF, $10 \mu \mathrm{g} / \mathrm{ml}$ leupeptin and $10 \mathrm{mg} / \mathrm{ml}$ aprotinin). Protein concentrations were determined by Bradford assays. Samples of extract containing equal amounts of total protein were resolved on $8.0 \%(\mathrm{wt} / \mathrm{vol}) \mathrm{SDS}-\mathrm{PAGE}$ and transferred to nitrocellulose membrane, which was blocked with $3 \%$ blocking buffer and then was incubated with polyclonal anti- $\beta$-catenin (dilution 1:500), monoclonal anticyclinD1 (dilution 1:500) and monoclonal anti-c-Myc (1:500) respectively. Then the membrane was incubated with the peroxidase-conjugated secondary antibody for $40 \mathrm{~min}$. The blotting patterns were revealed using the ECL system (Roche, Mannhein, Germany). $\beta$-tublin was blotted as a control of protein loading.

\section{Reverse transcription PCR (RT-PCR)}

Total RNA was extracted from cells using Tripure reagent (Roche, IN, USA). The total RNA ( $1 \mu \mathrm{g})$ was used for a reverse transcriptional reaction (Promega, WI, USA). The primers sequence used for amplification of LEF-1 and TCF-4 were: LEF-1 F, 5'-CCAGCTA-
TTGTAACACCTCA-3', LEF-1R, 5'-TTCAGATGTAGGCAGCTGTC-3'; TCF-4F, 5'-TTCAAAGACGACGGCGAACAG-3', TCF-4R, 5'-TTGCTGTACGTGATAAGAGGCG-3'. Cyclophilin was amplified as internal control using following primers: $\mathrm{F}, 5$ 'GACAGCAGAAAACTTTCGTGC -3', R, 5' - TCCAGCCACTCAGTCTTGG-3'. The amplification of the LEF-1, TCF4 and Cyclophilin cDNAs was performed using Taq polymerase (Promega, WI, USA) with the following thermocycle parameters: 5 min at $94^{\circ} \mathrm{C}$ and 25 cycles of $40 \mathrm{~s}$ at $94^{\circ} \mathrm{C}, 1 \mathrm{~min}$ at $60^{\circ} \mathrm{C}$, and $1 \mathrm{~min}$ at $72^{\circ} \mathrm{C}$, followed by a final incubation at $72^{\circ} \mathrm{C}$. RT-PCR amplified fragments (LEF-1, 453bp; TCF4, 517bp, Cyclophilin, 600 bp) were analyzed by $2 \%$ agarose gel electrophoresis. Densitometric scanning of the bands was carried out by Syngene Gel image scanning system (Syngene, England). The resulting bands were quantified, and the relative amount of LEF-1 and TCF4 mRNA was calculated after normalization with cyclophilin mRNA detected in the same sample.

\section{Transfection, luciferase assay}

Transient transfection was carried out by the calcium phosphate precipitation method. For luciferase assays, $\beta$-galactosidase expression plasmid was cotransfected as an internal control to normalize transfection efficiency. Luciferase activities in cell lysates were determined with luminometer (Lumat LB 9507, Berthold, Germany) $48 \mathrm{~h}$ after transfection using a luciferase assay kit (Promega, WI, USA). Each transfection was performed in triplicate and was repeated at least three times.

\section{Colorimetric cytotoxicity assay}

Analysis of cell proliferation was performed by SRB assay. Cells $\left(1 \times 10^{4}\right.$ cells per well $)$ were seeded into 24 -well plates $24 \mathrm{~h}$ before $\beta$ catenin or TCF4 plasmids transfection. The SRB proliferation activity assay was performed $48 \mathrm{~h}$ after transfection as described by Skehan[16] with slight modifications. Cultured cells fixed with trichloroacetic acid were stained for $30 \mathrm{~min}$ with $0.4 \%$ (wt/vol) sulforhodamine B (SRB) dissolved in $1 \%$ acetic acid. Unbound dye was removed by four washes with $1 \%$ acetic acid, and protein-bound dye was extracted with $10 \mathrm{~m} M$ unbuffered Tris base (pH10.5) for 5 min. OD value was read at $490 \mathrm{~nm}$ in Elx800 universal microplate reader (Bio-tech instrument, VT, USA).

\section{Colony formation assay}

BEL-7402 cells and L02 cells were transfected with dominant negative TCF- 4 and $\beta$-cateninS37A, respectively. After 14 days selection with G418, cells were stained with $0.5 \%$ crystal violet in $20 \%$ ethanol and photographed. The morphology and the number of colonies were counted under stereomicroscope.

\section{Statistics}

Data were presented as mean \pm standard deviation (SD). Statistical differences between the two groups were evaluated using the paired Student's t test. $\mathrm{P}$ values less than 0.05 were considered significant difference.

\section{RESULTS \\ Wnt signaling pathway was activated in HCC cell line BEL-7402}




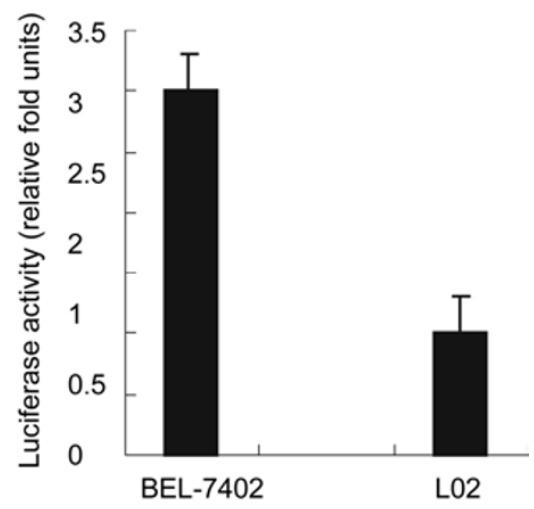

Fig 1. The Wnt pathway was activated in BEL-7402 cells determined by TOPFLASH reporter plasmid. BEL-7402 cells and L02 cells were transfected with the reporter plasmid (TOPFLASH or FOPFLASH). $\beta$-gal reporter construct was co-transfected to each sample to normalize transfection efficiency. The fold of BEL-7402 cells reporter activity to L02 cells reporter activity was indicated.

\section{A}
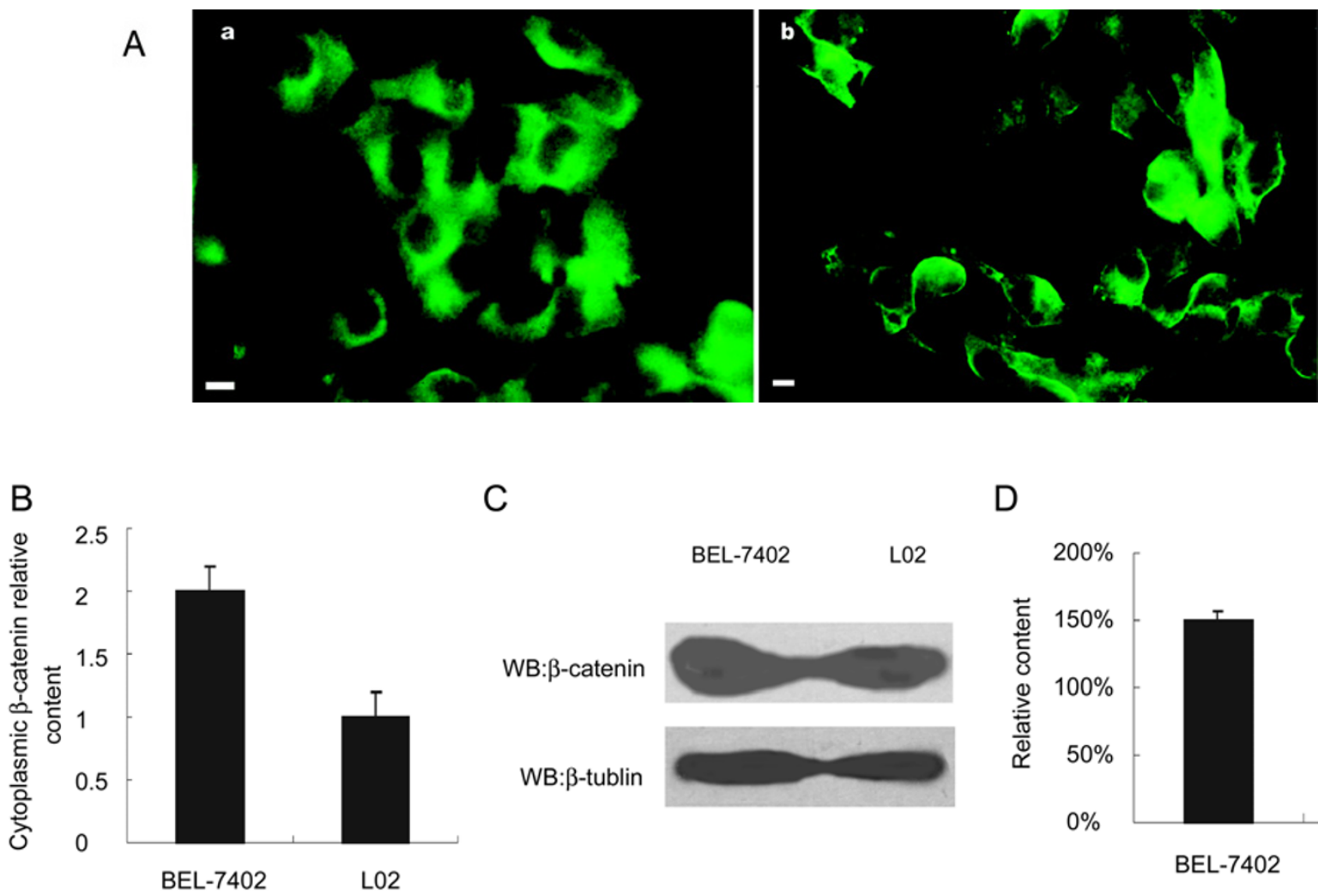

C

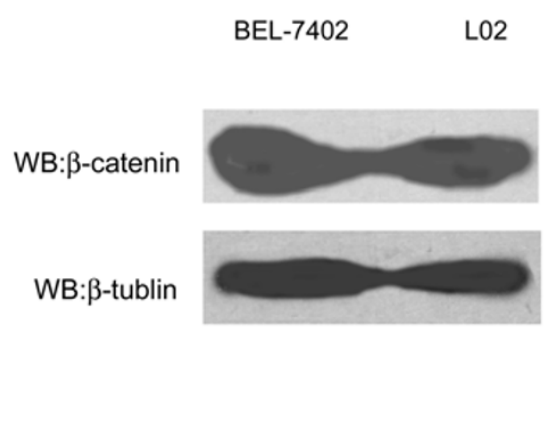

D

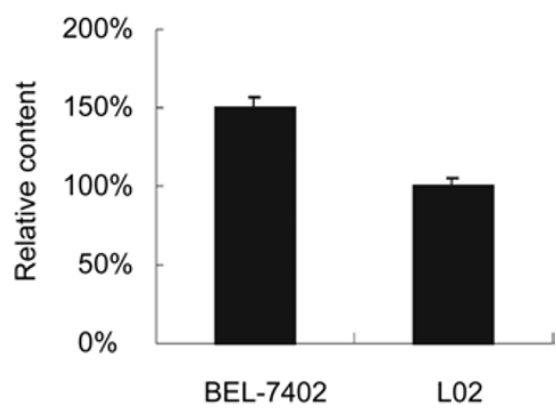

Fig 2. Expression of $\beta$-catenin protein in BEL-7402 cells detected by Western blotting analysis and Immunnofluorescence assay (A) Immunnofluorescence assay with $\beta$-catenin antibody in BEL-7402 cells and L02 cells. (a) BEL-7402 cells; (b) L02 cells. Bar, $10 \mu \mathrm{m}$ (B): Quantitative analysis of the immunofluorescence image in cytoplasmic $\beta$-catenin level of BEL-7402 and L02 cells. (C) BEL-7402 cells and L02 cells were lysed by cell lysis buffer and the isolated protein was subjected to immunoblotting with $\beta$-catenin antibody (upper panel) and $\beta$-tublin antibody as loading control (lower panel). (D) Expression levels relative to control $\beta$-tublin level were analyzed according to quantitative analysis of data of Fig $2 \mathrm{C}$.

L02 and BEL-7402 are extensively used HCC cell line in hepatoma research area in China, but the genetic background and the situation of Wnt components remain largely unknown. So we first investigated the activation of Wnt pathway by TOPFLASH luciferase reporter assay. As shown in Fig 1, the transcriptional activity of the TOPFLASH reporter in BEL-7402 was about 3 times higher than that in L02 cells, and no enhanced transcription was detected in cells transfected with the negative control FOPFLASH (not shown). The results suggested that Wnt 
A

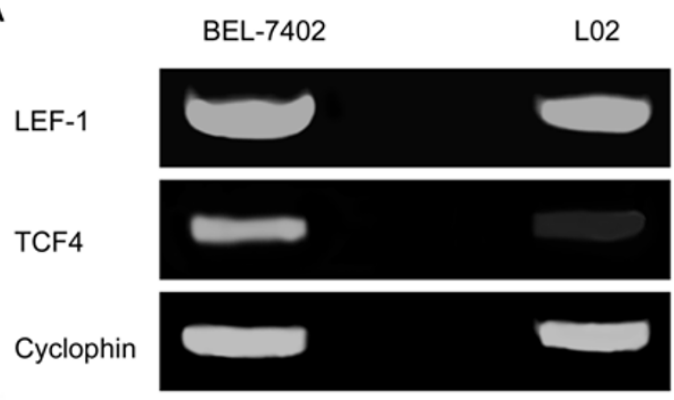

B

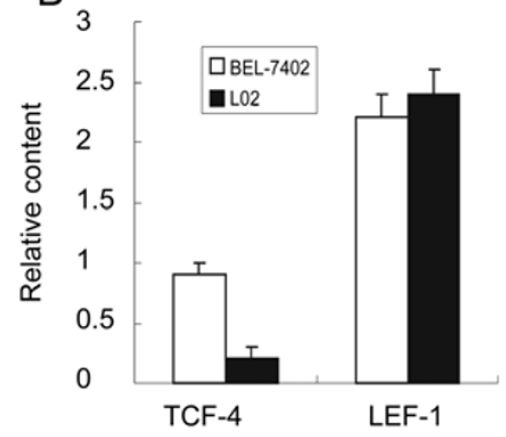

Fig 3. Predominant expression of TCF4 mRNA in BEL-7402 cells by RT-PCR analysis (A) One microgram of total RNA extracted from BEL-7402 or L02 cells was used for reverse transcription. PCR was then performed with the primers as described in Meterials and Methods. (B) Expression levels relative to control cyclophin mRNA level were analyzed according to quantitation of data of Fig 3A.

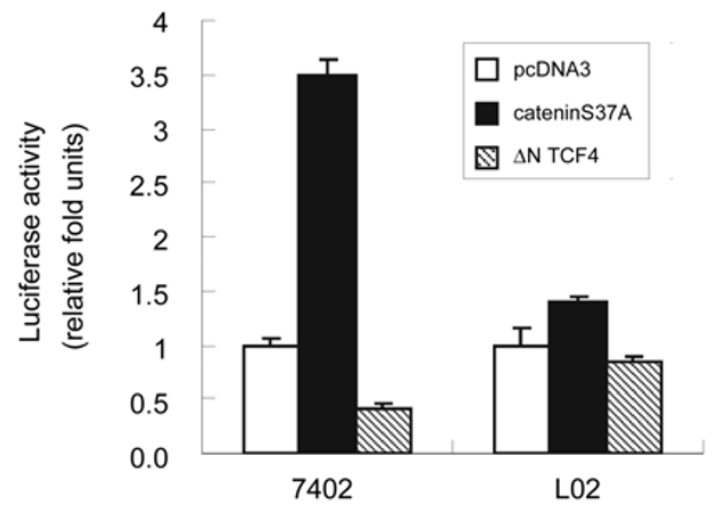

Fig 4. Effect of cateninS37A and $\triangle \mathrm{NTCF} 4$ on Wnt pathway in BEL-7402 cells and L02 cells Reporter gene assay with TOPFLASH in BEL-7402 cells and L02 cells. Cells were transfected with $0.5 \mu \mathrm{g}$ TOPFLASH, co-transfected in the combination of $1 \mu \mathrm{g} \beta$ cateninS37A or $\beta \Delta$ NTCF 4 constructs. $\beta$-gal reporter construct was co-transfected to normalize the transfection efficiency.

pathway was activated in HCC cell lines.

\section{The accumulation of $\beta$-catenin and high expression of TCF4 mRNA in HCC BEL-7402 cells}

To define which component of Wnt signaling pathway was changed in HCC cell line BEL-7402, we first used immunofluorescence staining to test the subcellular localization of $\beta$-catenin. Fig 2A showed that BEL-7402 cells were intensively stained in the cytoplasm, but not in nucleus, with very weak membrane staining comparing with L02 cells. The fluorescence intensity of $\beta$-catenin in BEL-7402 cytosole was 2 fold higher than that in L02 cells (Fig 2B). This results was confirmed by western blotting of $\beta$-catenin shown in Fig $2 \mathrm{C}$ and $2 \mathrm{D}$ that $\beta$ catenin level was $50 \%$ higher in HCC cells BEL-7402 than that in L02 cells $(\mathrm{p}<0.05)$. This suggested that the inap-

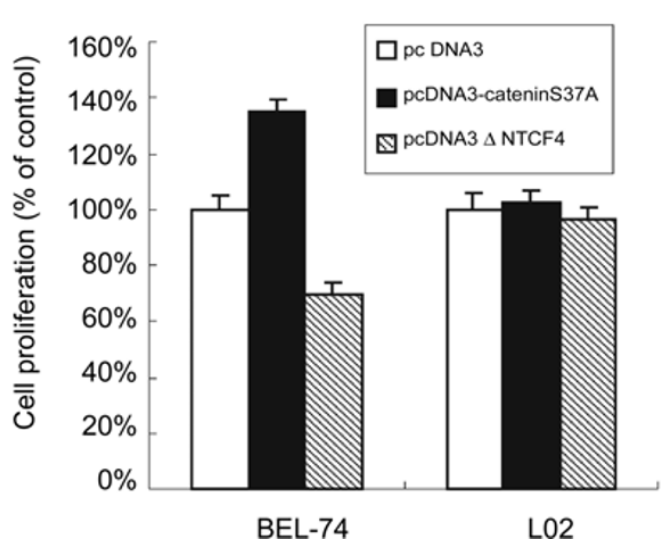

Fig 5. Effect of $\beta$-catenin and $\triangle$ NTCF 4 on the growth of BEL-7402 and L02 cells BEL-7402 cells and L02 cells were transfected with $\beta$ catenin or $\triangle \mathrm{NTCF} 4$ construct. The proliferation of the cells was determined by SRB assay.

propriate activation of Wnt pathway in BEL-7402 cell line was at least partially due to the accumulation of $\beta$-catenin.

The accumulated $\beta$-catenin need to bind to $\mathrm{LEF} / \mathrm{TCF}$ transcription factors to activate the target gene expression, so we further examined whether LEF/TCF transcription factor was also involved in the activation of Wnt pathway in HCC cells. We checked the mRNA level of LEF1 and TCF4 in BEL-7402 cells and L02 cells by semi-quantitive RT-PCR analysis. Fig 3 showed that TCF-4 mRNA was 3 times higher expressed in BEL-7402 cells than that in L02 cells, in contrast, LEF-1 mRNA level in BEL-7402 cells did not change comparing with that in L02 cells. The result suggested that the aberrant Wnt pathway may be due to both the enhanced expression of TCF4 gene and the accumulation of $\beta$-catenin. 


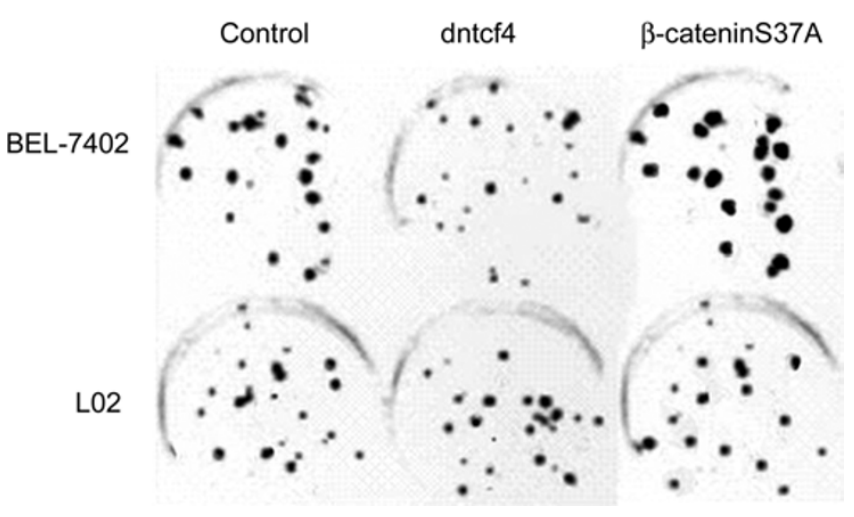

Fig 6. Colony-formation assay on BEL-7402 cells and L02 cells transfected with dominant-negative TCF-4 and cateninS37A BEL7402 cells and L02 cells were transfected with dominant-negative TCF-4 and cateninS37A and selected with G418, respectively. After 14 days's selection in G418, cells were stained and photographed.

\section{The accumulation of $\beta$-catenin stimulated BEL-7402 cells proliferation}

To further evaluate the function of accumulated $\beta$ catenin on BEL-7402 cell proliferation, we constructed the $\beta$-cateninS37A mutant plasmid, whose serine residue (S37) was mutated into alanine residue. Thus the phosphorylation of $\beta$-catenin by GSK-3 $\beta$ is inhibited and then the subsequent ubiquitination is blocked, which leads to $\beta$-catenin accumulation. As shown in Fig 4, the reporter gene assay showed that the Wnt pathway was highly activated by $\beta$-cateninS37A overexpression in BEL-7402 cells, but only slightly activated in L02 cells. The SRB assay (Fig 5) also showed that the proliferation of BEL7402 cells was accelerated by $\beta$-cateninS37A overexpression but that of L02 cells was only affected slightly. The result was further confirmed by the colony-forming assay (Fig 6). BEL-7402 cells expressing $\beta$-cateninS37A resulted in the increase of colony size, but no change in the number of colonies. But L02 cells expressing $\beta$ cateninS37A had no change in the number and size of colonies. These results suggested that $\beta$-catenin played important role in BEL-7402 cells proliferation.

\section{$\beta$-catenin governed BEL-7402 cells proliferation by regulating cyclinD1 protein level and $\mathrm{c}-\mathrm{Myc}$ protein level}

We further postulated that $\beta$-catenin promoted cell proliferation by activating cyclin $D 1$ and $c-m y c$, two of target genes of Wnt pathway. The luciferase reporter assay (Fig 7A) and western blotting analysis (Fig 7 B) showed that the expression of cyclin D1 and c-Myc were increased by $\beta$-cateninS37A in BEL-7402 cells, but not in L02 cells.
A

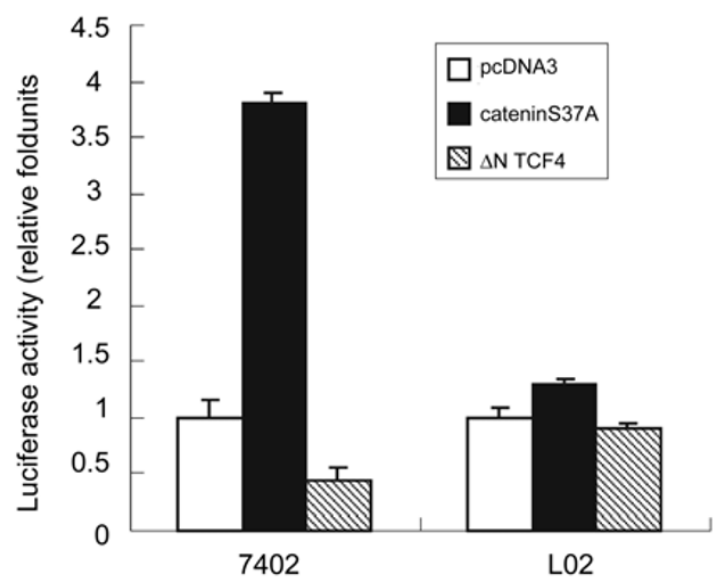

B

L02

BEL-7402

Control $\beta$-cetenin dnTCF4 Control $\beta$-catenin dnTCF4

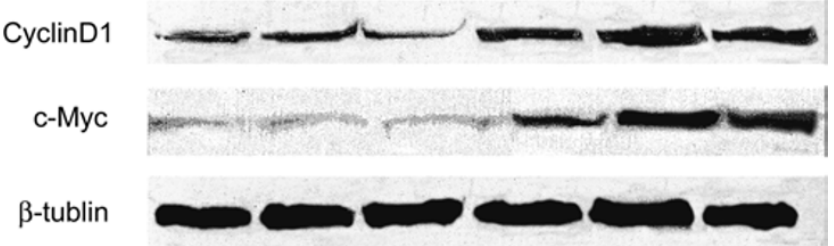

Fig 7. $\beta$-cateninS37A and DN TCF4 affect cyclin D1 and c-myc expression (A) Cyclin D1 reporter construct was introduced into BEL-7402 cells and L02 cells together with $\beta$-cateninS37A or $\triangle$ NTCF4. $\beta$-gal construct was co-transfected as control. The assay was performed $36 \mathrm{~h}$ after transfection. (B) Western blotting analysis of cells transfected with $\beta$-cateninS37A and dnTCF4. Cell extracts were prepared $48 \mathrm{~h}$ after transfection and the blot was first probed with cyclin D1 antibody and c-myc antibody. Subsequently, the identical membrane was probed with $\beta$-tublin antibody to indicate that equal amounts of protein loaded in each lane.

The result indicated that high expression of cyclinD1 and c-Myc caused by Wnt pathway activation was the reason of BEL-7402 cell proliferation.

Dominant negative TCF4 mutant suppressed BEL7402 cells proliferation and decreased cyclinD1 and c-Myc expression

To test whether TCF 4 was necessary to BEL-7402 cells growth, loss of function studies were carried out with a dominant negative TCF4 (DNTCF4 ). The TCF4 mutant deleted 2-53 amino-terminus residues which was $\beta$-catenin binding domain. This is a dominant-negative TCF4 form that can block Wnt signal pathway (Fig 4). DNTCF4 also could inhibit the proliferation of BEL-7402 cells (Fig 5 ) and decrease the colonies' size of BEL-7402 cells (Fig 6). As shown in Fig 7, DNTCF4 overexpression could lead to an decreased expression of the cyclinD1 and 
c-Myc in BEL-7402 cells. The results suggested that dominant negative TCF4 could suppress HCC cells proliferation and TCF4 could be used as a gene therapy target of HCC.

\section{DISCUSSIONS}

The aberrant activation of the Wnt- $\beta$-catenin pathway was noteworthy in HCC carcinogensis[18, 19]. $\beta$-catenin gene mutation and protein accumulation in $\mathrm{HCC}$ has been reported[19], and it has been shown that the accumulation of $\beta$-catenin may be the results of the mutation of either $A P C, \beta$-catenin or AXIN1 gene in Wnt pathway [11]. In this report, we confirmed that Wnt pathway was really inappropriately activated in BEL-7402 cells and this activation accounted for the accelerated proliferation of BEL-7402 cells. But activation of Wnt pathway by overexpre-ssion $\beta$-cateninS37A had no effect on L02 cells, so there might be other components of Wnt pathway governing the proliferation of BEL-7402 cells. Harada et al [21] also showed that the Wnt pathway activation by stabilizing $\beta$-catenin was not sufficient for hepatocarcinogenesis, additional mutations or epigenetic changes may be required.

TCF4, an important molecule of Wnt pathway, is a member of TCF family and plays many important roles in tumorigenesis[20]. TCF-4 encodes a transcription factor that interacts functionally with $\beta$-catenin to transactivate target genes expression. High level of TCF-4 expression has been identified in colon cancer, mammary carcinoma and a variety of colorectal cancer cells[22]. In the present study, we have found that TCF4 mRNA was predominant expressed in BEL-7402 cells. Further studies demonstrated that the transcriptional activity of Wnt pathway could be blocked by $\triangle \mathrm{NTCF} 4$ overexpression. This indicated that TCF4 might be another key factor in Wnt pathway involved in HCC cells proliferation. This point was confirmed by further experiments that both the proliferation and colony formation assay of HCC cells were suppressed by $\triangle \mathrm{NTCF} 4$ overexpression.

But we still can't exclude the possibility that other components of Wnt signal pathway altered in BEL-7402. It has been reported that there are $\beta$-catenin, and AXIN1 gene mutation found in $\mathrm{HCC}[12]$. But we know nothing about the genetics background of BEL-7402 cell. The aberrant expression besides the gene mutation of the components of Wnt signal pathway might also account for the control of BEL-7402 cell proliferation.

Cyclin D1 and $c-m y c$ are two cell cycle progression genes. Cyclin D1 contains a TCF response element within its promoter region and is thought to be a rate-limiting mediator of the G1 to $\mathrm{S}$ phase transition in the cell cycle and be implicated in the development of cancer[23]. C-myc, a downstream target of the Wnt pathway, contributes to progression of a wide range of human and animal tumors [24]. C-Myc executes its multiple activities mostly through transcriptional regulation of the target genes. We showed that expression of cyclin D1 and c-Myc were strongly dependent on $\beta$-catenin expression in BEL-7402 cells. Blockage of Wnt pathway by $\triangle$ NTCF4 would result in growth arrest and expression decrease of cyclin D1 as well as c-Myc in BEL-7402 cells. These can explain why the proliferation of BEL-7402 cells could be stimulated by the accumulation of $\beta$-catenin and blocked by $\triangle$ NTCF4.

If these observations can be confirmed in other HCC cell lines, we suggested that TCF4 may be an effective therapeutic molecule for suppressing growth of HCC. Disruption of the TCF4- $\beta$-catenin interaction could be useful in treating $\mathrm{HCC}$, and this would provide a new insight into the gene therapy of HCC.

\section{ACKNOWLEDGEMENTS}

We are grateful to Dr. O. Tetsu, Dr. F. McCormick, Dr. H. Clevers, Dr. A. Arnold and Dr. R. Pestell for their generous gift of the construct of pcDNA3TCF4, pcDNA3 dominant negative TCF4 and the CyclinD1 reporter plasmid. We would like to thank Dr. Fu XY for providing $\beta$-cateninS37A plasmid and Dr. Yin ZM for providing us with the control reporter plasmid $\beta$-gal-CMV. This reseach was supported by Natural Science Fund of Jiangsu Province 2000SWX000B501.

Received, Dec 25, 2003

Revised, Nov 10, 2003

Accepted, Nov 16, 2003

\section{REFERENCES}

1 Peifer M, Polakis P. Wnt signaling in oncogenesis and embryogenesis -a look outside the nucleus. Science 2000; 287:1606-9.

2 Pennisi E. How a growth control path takes a wrong turn to cancer. Science 1998; 281(5382):1438-9.

3 Hulsken J, Behrens J. The Wnt signaling pathway. J Cell Science 2000; 123:3545-9.

4 Huber AH, Weis WI. The structure of the $\beta$-catenin /E-cadherin complex and the molecular basis of diverse ligand recognition by beta-catenin. Cell 2001; 105:391-402.

5 Korinek V, Barker NPJ, Morin D et al. Constitutive transcriptional activation by a beta-catenin-TCF complex in APC(-/-) colon carcinoma. Science 1997; 275:1784-7.

6 Rubinfeld B, Albert I, Porfiri E. Binding of GSK3 $\beta$ to the APC $\beta$-catenin complex and regulation of complex assembly. Science 1996; 272:1023-6

7 Nakamura T et al. Axin, an inhibitor of the Wnt signalling pathway, interacts with $\beta$-catenin, GSK- $3 \beta$ and APC and reduces the $\beta$-catenin level. Genes Cells 1998; 3:395-403

8 Morin PJ, Sparks AB, Korinek V. Activation of beta-cateninTcf signaling in colon cancer by mutations in beta-catenin or 
APC. Science 1997; 75:1787-90

9 Ferruccio G, Volonte D, Brown AMC et al. Caveolin-1 expression inhibits Wnt/ $\beta$-catenin/Lef-1 signaling by recruiting $\beta$-catenin to caveolae membrane domains. J Biol Chem 2000; 275(30): 23368-77.

10 Rubinfeld B, Albert I, Porfiri E. Binding of GSK3 $\beta$ to the APC $\beta$-catenin complex and regulation of complex assembly. Science 1996; 272:1023-6.

11 Koch A, Denkhaus D and Albrecht S et al. Childhood hepatoblastomas frequently carry mutated degradation targeting box of the $\beta$-catenin gene. Cancer Res 1999, 59:269-73.

12 Satoh S, Daigo Y, Furukawa Y et al. AXIN1 mutations in hepatocellular carcinomas, and growth suppression in cancer cells by virus-mediated transfer of AXIN1. Nat Genet 2000; 24(3):24550.

13 Lawrence S. Beta-catenin and its multiple partners: promiscuity explained. Nature Stru Biol 2001; 8:484-7.

14 Mann B, Gelos M, Siedow A et al. Target genes of beta-catenin$\mathrm{T}$ cell-factor/lymphoid enhancer factor signaling in human colorectal carcinomas. Proc Natl Acad Sci 1999; 96:1603-8.

15 Charles, Omer, Patricia J, Miller, Ronald E Diehl, Astrid M, Kral. Identification of TCF4 Residues Involved in High-Affinity $\beta$-catenin Binding. Biochem Biophy Res Comm 1999; 256(3): 584-90.

16 Skehan P, Storeng R, Scudiero D et al. New colorimetric cytotoxicity assay for anticancer-drug screening. J Nat Cancer Inst 1990;
82:1107-12.

17 Wang X, Xiao Y, Mou Y, Zhao Y, Blankesteijn WM, Hall JL. A role for the beta-catenin/T-cell factor signaling cascade in vascular remodeling. Circ Res 2002; 90(3):340-7.

$18 \mathrm{Xu} \mathrm{XR,} \mathrm{Huang} \mathrm{J,} \mathrm{Xu} \mathrm{ZG} \mathrm{et} \mathrm{al.} \mathrm{Insight} \mathrm{into} \mathrm{hepatocellular} \mathrm{car-}$ cinogenesis at transcriptome level by comparing gene expression profiles of hepatocellular carcinoma with those of corresponding noncancerous liver. Proc Natl Acad Sci 2001; 98(26):15089-94.

19 Coste A, Romagnolo B, Billuart P et al. Somatic mutations of the $\beta$-catenin gene are frequent in mouse and human hepatocellular carcinomas. Proc Natl Acad Science 1998; 95:8847-51.

20 Graham TA, Ferkey DM, Mao F, Kimelman D, Xu W. TCF4 can specifically recognize beta-catenin using alternative conformations. Nat Struct Biol 2001; 8(12):1048-52.

21 Harada N, Miyoshi H, Murai N et al. Lack of Tumorigenesis in the mouse liver after adenovirus-mediated expression of a dominant stable mutant of beta-Catenin. Cancer Res 2002; 62(7): 1971-7.

22 Hovanes K, Li TW, Munguia JE et al. Beta-catenin-sensitive isoforms of lymphoid enhancer factor-1 are selectively expressed in colon cancer. Nat Genet 2001; 28:53-7.

23 Tetsu O, McCormick F. beta-catenin regulates expression of cyclin D1 in colon carcinoma cells. Nature 1999; 398:422-6.

$24 \mathrm{He}$ TC, Sparks AB, Rago C et al. Identification of c-Myc as a target of the APC pathway. Science 1998; 281:1509-12. 